\title{
Josué de Castro e o pensamento social brasileiro
}

\author{
Josué de Castro and Brazilian social thought
}

Mercês de Fátima dos Santos Silva ${ }^{1}$

Everardo Duarte Nunes ${ }^{1}$

${ }^{1}$ Faculdade de Ciências

Médicas, Universidade

Estadual de Campinas.

Cidade Universitária,

Barão Geraldo. 13081-

970 Campinas SP Brasil.

merces20@yahoo.com.br

Abstract This article highlights the fact that the work of Josué de Castro brings to light some of the most relevant interpretations on the Brazilian food situation, launching the first proactive manifesto for the construction of a social policy on food in Brazil. Underpinning this debate, there are aspects of the process of construction of the Nation State, national development and the role of the Brazilian intellectuals. Such issues are added to the author's concern with the formation of proactive measures that could lead to social change and redefinitions of the conditions of social exclusion of a significant portion of the Brazilian population. We start from the assertion that his work is part of broader interpretations about Brazil, which need to be revisited.

Key Words Josué de Castro, Geography of hunger, Brazilian social thought
Resumo Este artigo aponta que a obra de Josué de Castro traz à tona algumas das interpretações mais relevantes sobre a situação alimentar brasileira, lançando o primeiro manifesto-propositivo para construção de uma política social de alimentação no país. Subjazem a esta sua discussão os aspectos do processo de construção do Estado-nação, o desenvolvimentismo nacional e o papel dos intelectuais brasileiros. Tais questões somam-se à preocupação do autor com a formação de ações propositivas que levassem às mudanças sociais e redefinições das condições de exclusão social de parcela significativa da população brasileira. Partimos da afirmação que sua obra faz parte das interpretações mais amplas sobre o Brasil, sendo necessária ser revisitada.

Palavras-Chave Josué de Castro, Geografia da fome, Pensamento social brasileiro 


\section{Introdução}

Os grandes temas dos estudos de Josué de Castro, o problema da fome e da subalimentação, estão presentes na trilogia: Geografia da Fome (1946), Geopolítica da Fome (1951) e o Livro Negro da Fome (1960) e entram na agenda política do país a partir das discussões fomentadas nesses escritos. Tanto é assim que sua trajetória intelectual se confunde com os marcos norteadores da Política de Segurança Alimentar no Brasil ${ }^{1-6}$.

É talvez por isso que partimos do pressuposto que Josué de Castro seja um autor controverso no debate intelectual brasileiro, oscilando entre o reconhecimento na construção de instituições científicas e políticas para formulações e ações de combate à fome e o esquecimento de seu legado intelectual nos debates acadêmicos como intérprete da realidade social brasileira, especificamente no campo disciplinar do pensamento social brasileiro ${ }^{1}$.

Para alguns de seus estudiosos, Josué de Castro está indissociável e indiscutivelmente no palco do pensamento social brasileiro ${ }^{7}$. Contudo, na hierarquia dos intérpretes brasileiros encontra-se no rol dos "esquecidos, esquecidos porque pouco lidos".

Entretanto, aponta-se que o ostracismo da obra de Castro é datado, deve-se ao Golpe Militar de 1964, momento em que teve seus direitos políticos subtraídos, integrando a primeira lista dos cassados da ditadura, ao lado de João Goulart, Jânio Quadros, Miguel Arraes, Darcy Ribeiro, Francisco Julião, Carlos Prestes, Leonel Brizola, dentre outros, quando teve seus livros banidos das prateleiras das bibliotecas das universidades e das escolas brasileiras ${ }^{9,10}$.

Atualmente, a produção sobre o legado intelectual de Castro está em crescente expansão no campo de conhecimento das Ciências Sociais, da Geografia e da Nutrição, áreas que lideram as discussões. Em geral, são produções de um grupo de autores reduzidos, militantes do pensamento castrino, que tentam trazer a importância do nosso autor para a interpretação do Brasil. São produções, em sua maioria, marcadas por aspectos memorialísticos com objetivos de reavivar a obra e/ou artigos comemorativos e em homenagem ao cientista e/ou político ${ }^{1}$.

Sendo assim, continuamos tensionando a assertiva de que as produções com posicionamento crítico e epistemológico de seu legado intelectual ainda são escassas e apresentam lacunas que precisam ser exploradas no debate público atual da sociedade brasileira, sobretudo, no campo da Saúde Coletiva.
Como nos revela Ribeiro ${ }^{11}$, Silva ${ }^{9}$ e Cândido $^{12}$, antes do Golpe Militar de 1964, seus textos, Geografia da Fome (1946), Geopolítica da Fome (1951) e O Livro Negro da Fome (1960), tiveram grande impacto na geração de 1950 e 1960 . Essas obras promoveram o debate público e influenciaram as produções acadêmicas acerca de uma realidade incômoda, a constatação de que há na sociedade brasileira alto índice de miserabilidade e de exclusão social, suscitando a questão reveladora de sua postura acerca do papel do conhecimento e do pensamento na produção de ações políticas voltadas para o combate das mazelas sociais.

Ribeiro $^{11}$ e Candido ${ }^{12}$ nos chamam atenção para o fato de que a obra de Castro, envolta do debate sobre a nossa desigualdade social, possui uma lucidez para explicar as questões sociais e políticas acerca da nossa modernidade, que até então estavam sendo travadas, como nos revela Souza $^{13}$, sob a fragmentação do conhecimento e a fragmentação da realidade. Para Souza ${ }^{14}$, essas fragmentações ocorrem porque nosso pensamento social brasileiro é conservador e foi produtor de uma inversão especular da realidade brasileira.

Grosso modo, essa inversão especular produz ideias que parecem ser singulares e contrapostas ao pensamento conservador, mas não são. Por vezes, tais ideias promovem um espectro da nossa realidade a partir de ideias vindas de fora, produzindo uma sociologia brasileira "inautêntica"14, sociologia que Castro classificava como não comprometida e ocultista da nossa realidade.

Não é nosso objetivo tecermos uma análise sobre a inautenticidade da sociologia brasileira, pressupondo que a produção do conhecimento brasileiro seja a mera repetição das ideias exógenas, mas testar nosso pressuposto de que há questões na obra castrina capazes de gestar atualmente uma crítica descolonizadora no pensamento social brasileiro, que nos inspira a crer no projeto de humanidade que seja capaz de superar os danos impostos historicamente pela lógica modernidade-colonialidade.

Ademais, como aponta Bastos ${ }^{15}$, várias questões atualmente elucidadas nos debates acadêmicos e públicos sobre a realidade social brasileira foram, de diversas formas, objetos de reflexão dos autores brasileiros ao longo dos anos: a problemática da emancipação, o direito à diferença, os limites da liberdade, do reconhecimento e da exclusão social, temáticas recorrentes sobre a formação de um projeto nacional no cenário de colonialismo, escravidão, sucessivos proces- 
sos antidemocráticos e extrema desigualdade na distribuição de renda. Entretanto, nos últimos tempos, o pensamento social brasileiro vem colocando estas mesmas questões sob outra ótica, conduzindo à produção de novas categorias analíticas que buscam apreender os fenômenos sociais em suas singularidades, com continuidades e descontinuidades com o debate anterior.

Entre os elos de continuidades e descontinuidades está o processo de descentramento teórico que vem ocorrendo ao longo das últimas décadas no pensamento social brasileiro. Esse descentramento refere-se ao conjunto de textos e trabalhos que questionam o fundamento eurocêntrico das ciências sociais e afirmam a necessidade de se levar em conta lugares de discursos intelectuais tidos como alternativos e/ou "periféricos"16. Descentramento, que ao nosso ver, pode também ser encontrado na obra de Castro.

Assim, partimos do entendimento de que os debates anteriores, continuam enraizados no constructo simbólico ambíguo, não resolvido, construído a partir do ideário da democracia social. Estes debates nos obrigam a exercer o descentramento para nosso autoconhecimento e reconhecimento da nossa sociedade tal como ela se apresenta, sem cópias padronizadas de culturas externas a nossa, sem naturalização de desigualdades sociais, causado por uma leitura distorcida da nossa realidade ${ }^{14}$.

Essa distorção ou miopia sobre o real, superficial, fragmentada e seletiva que aponta para os efeitos e as consequências dos problemas sociais brasileiros e não para sua causa, ou para as várias causas, como contemporaneamente Castro e outros intérpretes do "rol dos poucos lidos" apontavam. Castro denunciava que a visão descomprometida com a realidade fazia do Brasil um país de famintos, que empurrava para $1 / 3$ da população a condição de exclusão e miséria, que, segundo Souza $^{17}$, se produziu e se reproduziu durante todo o processo de modernização à brasileira, gerando a "ralé brasileira".

A extensa introdução justifica-se porque queremos apresentar dois limites analíticos presentes neste artigo, de um lado, a afirmação de que a obra de Castro não tem a devida atenção nos debates acadêmicos e públicos, e, por outro lado, apontarmos que o descortinar da sua obra possibilita certo entendimento da sociedade atual. Para tanto, abordaremos inicialmente a sociologia comprometida de Castro e seu debate com a "sociologia ocultista", suscitando questões sobre o papel do intelectual em Castro. Em seguida, apresentaremos, o que consideramos, as principais temáticas presentes na sua obra. Acreditamos, como Souza ${ }^{13}$, que uma das formas de homenagear uma obra científica seja a partir do diálogo crítico com um autor lúcido.

\section{Sociologia comprometida}

Castro $^{18}$ argumentava que essa naturalização da desigualdade não foi operada apenas pela elite política, mas também pela elite intelectual brasileira, que de forma disfarçada ou escancaradamente optava por aderir e justificar este ato. Castro ${ }^{19}$ constatava que parte da nossa sociedade, mais numerosa e faminta, estava privada do direito primário: o de se alimentar. Para ele, a miopia da intelectualidade ou os óculos da ideologia dominante com seus interesses econômicos trabalhavam para esconder o fenômeno da fome, reprodutora da pobreza.

Assim, ao abrir as cortinas do nosso país, para apontar que somos um país famélico, Castro ${ }^{20}$ não operou apenas no plano das ideias passageiras com afirmações frágeis de que é possível reverter a situação de miserabilidade da nossa nação por um decreto do Estado, pelo contrário, analisou que a fome é um problema com várias ramificações aparentemente desarticuladas entre si, mas que estão estritamente vinculadas e, no nosso caso, complexificam-se dada a extensão territorial, as condições do homem tropical, a diversidade cultural do povo e a cultura política da elite brasileira. Sendo assim, os problemas sociais, tendo a fome como eixo central, não poderiam ser baseados numa relação masoquista entre senhor de escravo (bem alimentado) e os escravos (alimentado), conforme relatado por Freyre $^{21}$.

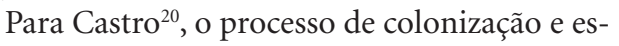
cravidão brasileira foi violento, como qualquer outra forma de escravidão, trazendo consequências socioambientais e culturais para a alimentação e nutrição nacional, sendo o fenômeno da fome observado tanto entre os senhores quanto nos escravos. Entre os escravos, a fome operou consequências devastadoras do ponto de vista moral, cultural e político, por serem claramente marginalizados, humilhados e privados de direitos sociais básicos.

Tal como Celso Furtado e outros autores que recepcionaram a obra de Mannheim no Brasil, Castro enfatiza em seus textos que a reflexão teórica, o pensamento produzido pelos intelectuais de uma sociedade, tem a incumbência de fazer com que a sociedade seja revelada em suas nuanças fundamentais, em seus aspectos formadores 
e em sua constituição. Mais que isso, caberia ao intelectual um esforço de ação transformadora através de uma atividade intelectual que desvende as relações sociais e aponte caminhos para a ação prática ${ }^{22}$, tendo em vista que a obra intelectual tem como função a intervenção social ${ }^{18}$.

Entretanto, esta intervenção intelectual terá sempre um compromisso com o rigor científico, mas não com o "fanatismo do cientificismo estreito, detentor de verdades parciais e sempre temeroso de toda aventura da inteligência que possa alterar a disposição clássica” de ciência ${ }^{18}$. Mas um rigor científico que traduza especulações organizadas sobre a realidade, a partir de métodos produtivos que possam gerar ações propositivas sobre o real e não quadros pitorescos da realidade, fato que lhe chamou atenção sobre a formação da sociologia no Brasil nos anos de 1930 e que o levou a denominar de "Sociologia Pitoresca".

Neste texto, "Sociologia Pitoresca"18, o autor critica certas formas de estudos sociológicos que para ele produziram uma ditadura pitoresca dentro do quadro ecológico da sociologia brasileira, pintando "a paisagem cultural como exótica para "inglês ver". Tais críticas revelaram as fortes divergências existentes com Freyre, especialmente, em relação às condições de vida, habitação e alimentação da sociedade brasileira. Embora Castro $^{20}$ admita que Freyre ${ }^{21}$ tenha abordado com certa inteligência tais temáticas, para ele, porém, o autor de Casa Grande \& Senzala havia se utilizado mais de aspectos pitorescos do que propriamente de aspectos teórico-metodológicos.

Bem verdade que as trocas de acusações foram recíprocas e iniciaram-se em 1932, com a tese de Livre-docência "O problema fisiológico da alimentação no Brasil” defendida por Castro pela Faculdade de Medicina do Recife e publicada em 1933. As ideias apresentadas neste estudo contestadas por Gilberto Freyre em "Casa Grande \& Senzala" 21 , evidentemente por questões de delimitação e competência de saberes.

Castro $^{20}$ questiona-se sobre como pode Freyre $^{21}$, que cita autores consagrados na área da Nutrição, não conhecer alguns conceitos básicos de Química e de Biologia que lhe permitiriam penetrar minimamente nos assuntos especializados de alimentação, chegando até a diferenciar proteína de albuminoides como sendo duas coisas diferentes, quando são a mesma coisa. Além disso, Castro interroga-se como se pode afirmar que os negros são mais bem alimentados do Brasil.

Tratando da alimentação dos escravos ele [Freyre] diz: "sua abundância em milho, toucinho e feijão recomenda-a como regime apropriado ao duro esforço exigido do escravo agrícola”. Ora esse regime que o sociólogo julga racional é capaz de matar por deficiência até um inativo quanto mais um escravo forçado a trabalhos exaustivos. Onde, neste regime se encontram albuminas de alto valor biológico contendo ácidos aminados indispensáveis ao equilíbrio nutritivo? (Diário da Manhã, 3 de fevereiro de 1934)

Para Castro ${ }^{20}$, Freyre faz uma abordagem inteligente em Casa Grande \& Senzala, na medida em que teria mostrado a importância da influência negra na formação socioeconômica, sobretudo, no que se refere a diversidade alimentar e seus cultivos, despertando para intrínseca relação entre alimentação e sociedade, além de despertar interesse pelo problema do negro. Cabe notar que tanto Castro e Freyre, ao utilizarem-se do enfoque cultural, socioeconômico e geográfico, chegam a pontos comuns, como, por exemplo, que o nosso padrão alimentar é deficiente e instável. Entretanto, Castro atribuiu esta conclusão também ao fato de que a Saúde Pública teria provocado uma mudança nos estudos sociológicos, ao dar valor aos processos biológicos, às condições gerais de vida e de higiene como fatores socioantropológicos

Já se vai tornando frase feita entre os modernos sociólogos de que o homem é fraco no Brasile o Brasil pobre no mundo por falta de alimentação adequada do seu povo e de outros requisitos de higiene coletiva. Com todo o exagero que contenha esta afirmativa tomada assim rigidamente sem uma certa prudência científica, ela é bem mais salutar ao país do que a afirmativa retórica dos antigos discursos politicos de que - O Brasil é um país feliz onde ninguém morre de fome $e^{23}$.

Entretanto, o grande erro de Freyre, o que demonstrava a fragilidade da sua interpretação, estava em concluir que os mais bem alimentados do padrão alimentar brasileiro se encontravam em duas classes antagônicas: o senhor de engenho e os escravos. Isto significaria que as demais camadas sociais dentro do regime econômico, os homens livres, constituídos por mestiços e caboclos, apresentavam maior déficit no consumo de alimentos. Para Castro, relacionada aos interesses econômicos, subjazia na ação do senhor de engenho a necessidade de abastecer o escravo de maior teor energético. Não havia preocupação com o fornecimento dos alimentos protetores do organismo, isso fazia com que as senzalas fossem espaços de afecções, avitaminoses, tuberculose e tantos outros males. Além disso, a monocultura açucareira e o latifúndio foram as grandes causas da problemática urbana, aliás, de todo o país. 
O nosso autor ressalta que esse descompromisso assumido por Freyre continuou em Sobrados e Mocambos ${ }^{24}$, ao descrever a importância dos mocambos como valor nacional, esquecendo que são habitações construídas em locais inapropriados para a saúde humana e fruto do êxodo rural causado pelo agravamento da fome da população açucareira e do Sertão Nordestino, habitadas em sua maioria por negros e mestiços.

Castro considerava os mocambos como verdadeira senzala remanescente, que revelava a produção e a reprodução das desigualdades sociais, para além da poesia das manifestações socioculturais realizadas pelos negros e mestiços, seus principais habitantes. Para Castro, o emprego do método sociológico, sem conhecimento integral do problema mediante pesquisa sistemática, gerava distorções que nada contribuiriam para solução dos nossos problemas, pelo contrário, mostrava-se o desserviço intelectual descomprometido com a nação. Para ele era necessário a criação de uma Sociologia Comprometida.

Cabe enfatizar que, as aproximações e o afastamento da obra de Castro com Gilberto Freyre revelam uma das principais características do legado intelectual de nosso autor, o diálogo intelectual com diversas tendências e atores "sem uma filiação que o limitasse a determinada perspectiva”, desenvolvendo um legado marcado por convergência, divergência, renovações e singularidades em relação ao pensamento emergente em sua época, com intuito de revelar as práticas de uma ciência engajada. Ao eleger a temática da fome como objeto de estudo, Castro revelou sua perspectiva de ciência engajada e o papel dos intelectuais, que seria não construir verdades absolutas universais, mas possibilidades de elaborações e planejamentos para a construção de uma sociedade equitativamente mais justa.

Claramente, podemos perceber na obra de Castro, no que diz respeito ao debate entre alimentação, saúde e sociedade, três momentos distintos e dialógicos entre si, que se comunicam e avançam na direção da compreensão da produção da pobreza no Brasil. O primeiro momento corresponde à tese "Mal de fome e não de raça" (1930-1940); O segundo momento de (19401946) consolidação da ciência da nutrição e o último (1946-1960), fase em que o autor consolida as bases do seu pensamento em relação à desigualdade social à brasileira.

\section{A tese mal é de fome e não de raça e a construção da nacionalidade}

Em seus estudos sobre a fome, Castro ${ }^{25}$ parte da assertiva de que $A$ fome pode intervir como força social, capaz de modificar a conduta e o comportamento do homem, agindo, assim, em consequência, como um fator de desajuste entre indivíduos, povos e nações. Esta lógica operada por Castro, inicialmente, nos anos de 1930, leva-o a elaborar a tese "mal é de fome e não de raça", apresentando rupturas, continuidades e descontinuidade com o debate brasileiro iniciado no final do século XIX, colocando em pauta as bases científicas da alimentação racional para explicação de determinados males sociais. $\mathrm{Na}$ verdade, essa tese, em suas prerrogativas, tornou-se um marco na história da ciência da Nutrição, que assume o debate de fome/subalimentação, antes analisado como questão apenas de higienização pelos médicos sanitaristas ${ }^{26-28}$.

Desse modo, o elo de continuidade com o debate anterior, sob influência das ideias de Goubineau de superioridade da raça ariana pura e o determinismo do meio, foi estabelecido com base na reinterpretação dessas análises que dominaram o debate público. Castro ${ }^{18}$ considerava o debate de raça pura, ultrapassado e etnocêntrico, ressaltando que outros autores como Manoel Bonfim, já havia recolocado tais questões no debate nacional, além disso, o mal social que nos atinge, fome/subalimentação, também atinge outros países com "clima não tão tropical como o nosso e onde não se processou um caldeamento com a raça”.

Grosso modo, sua tese "Mal de fome e não de raça", contribuiu para a sua passagem da antropologia física para antropologia cultural, retirando o processo de meio e raça da discussão genética, aproximando da teoria culturalista de Franz Boas, difundida no Brasil por Freyre. Entretanto, como assinala Lima ${ }^{26}$, se a teoria cultural se afastava do biológico em direção ao social, estas dimensões se reencontravam ao atribuir como o mal social a fome/subalimentação e a necessidade da formação de uma educação racional alimentar. Essa educação alimentar seria sistematizada pela ciência da nutrição, que reconstituiu o biológico "como fator de evolução social em novas bases".

Essa reconstituição do biológico em direção ao social sofreu forte influência do Movimento Sanitarista da Primeira República, que concentrava suas ações na explicação de que o Brasil estava doente e que seria necessário torná-lo 
sadio se quiséssemos construir a nacionalidade, colocando como agenda pública central do país os problemas de saúde, qualificando como científica a natureza de sua proposta. Assim, os adeptos dessa proposta divulgaram uma nova explicação para as origens dos "males do Brasil" longe do determinismo racial e climático e próximo das ideias de Euclides da Cunha (1902), que trazia a constatação de que éramos um país dividido entre o Brasil real, "atrasado" e o Brasil ideal, "moderno", mostrando os descompassos entre o Brasil urbano e rural ${ }^{29}$.

Assim, podemos notar que essa é a fase em que os estudos de Castro apresentam um franco diálogo com o positivismo, concentrando-se no método mais fisiológico, a partir da distinção entre o normal (população bem alimentada) e o patológico (doenças carenciais), com a finalidade de agir sobre este último com ações racionais na tentativa de constituição de uma educação alimentar, para que o Brasil alcançasse uma dieta alimentar que pudesse modernizar o país e curar a patologia da fome.

Além do debate travado com o Movimento Sanitarista I, essa tese de Castro, sofrerá forte influência dos romancistas nordestinos da geração de 1930, marcados por uma literatura crítica que procura desvendar realidade social brasileira. Com esses romancistas, enfatizaram-se as desigualdades sociais entre a casa grande e a senzala, à naturalização da problemática do Nordeste, sobretudo, em relação à seca, a questão do latifúndio e o processo perverso de modernização nas condições de vida dos trabalhadores no meio rural e urbano ${ }^{9,23}$.

Por isso, esta aproximação do diálogo entre a dimensão fisiológica/biológica com a dimensão sociocultural, embora no primeiro momento não se apresentasse tão óbvia, por perpassar dois tempos de sua obra (1930-1940 e 1940-1946), representava a tentativa de analisar a realidade brasileira a partir da relação estabelecida entre ambiente, sociedade, saúde e alimentação, compreendendo que o processo de saúde e doença tem relação com o meio, que, embora não determine, exerce influência sobre a saúde das populações.

Com os estudos realizados nesta fase, Castro forneceu modelos explicativos para o campo Ciência da Nutrição, indicando a temática fome/ subalimentação como problema central passível de ser compreendido a partir de marco biossociológico e pela interseção realizada entre o método fisiológico e o geográfico, primeiramente como meio de mapear as doenças carenciais provocadas pela má alimentação e, posteriormente, como método capaz de tornar compreensível, a partir da delimitação e do entendimento de fatores sócio-históricos, as causas desse mal e suas ramificações como produtores de desigualdade $\operatorname{social}^{4,26}$.

\section{Fome/subalimentação na agenda das políticas sociais do Brasil (1940-1946)}

Essa fase é marcada pelo reordenamento do conhecimento anteriormente produzido, numa perspectiva de síntese e de planejamentos para ações políticas. O emaranhado de debates em torno da denúncia de fome no Brasil, a partir de livros, artigos científicos e textos de jornais, levaram Castro a intensas reflexões e ao diálogo mais profícuo com a dimensão sociocultural da problemática da fome. Mais que isso, semeou a ideia de que a fome era um conceito político, colocando a ciência e a política como polos indissociáveis ${ }^{1}$.

Os estudos de Castro nos anos 1930, sobretudo os que utilizaram os inquéritos alimentares e abordaram a relação trabalho e alimentação, influenciaram a elaboração do Decreto Lei $n^{\circ}$ 2.162/1940, que instituiu o primeiro salário mínimo nacional. Este fato marcou a participação da intervenção estatal de forma mais expressiva, no que se refere à política social de alimentação, modelando, por vezes, de maneira contraditória, um conjunto de conceitos e noções que superaram a questão alimentar como problema fisiológico, individual, direcionando a problemática mais coletiva e social.

Em decorrência desses fatores, surgiu a necessidade de se repensar a ciência da Nutrição como uma ciência que teria um papel científico-político. Foi a partir das ideias de Castro, sob forte influência de Pedro Escudero, nutricionista argentino que insere a perspectiva da ciência da $\mathrm{Nu}$ trição como ciência do social na América Latina, que foram traçadas as nuances das diretrizes de uma política pública e a trajetória da alimentação humana em sua totalidade, da produção ao abastecimento, passando pelas dimensões culturais da alimentação e finalizando no consumo e seus impactos na saúde e nutrição das populações ${ }^{1}$.

Essa influência se dera nos anos de 1930, com o empenho de Castro em construir as bases da educação alimentar racional no Brasil, a partir da confluência entre o pensamento médico-nutrólogo com o pensamento social brasileiro. Tal confluência esteve presente em escritores e ensaístas brasileiros, que também influenciaram Castro ${ }^{28}$. Entretanto, o pioneirismo concedido a Castro 
deve-se à sua trajetória junto à burocracia estatal, a órgãos acadêmico-científicos e a organismos internacionais em que atuou e que auxiliou da criação, dentre eles, Serviço Central de Alimentação, em 1939; vinculado ao Instituto de Aposentadoria e Pensões dos Industriários (IAPI), depois convertido no Serviço de Alimentação da Previdência Social (SAPS), em 1941, que também foi presidido por Castro até 1941. Além da Sociedade Brasileira de Alimentação (SBA), em 1940; Serviço Técnico de Alimentação Nacional (STAN), em 1943; Instituto Técnico de Alimentação (ITA), em 1944; Arquivo Brasileiro de Nutrição, 1944, Comissão Nacional de Alimentação (CNA), (1945)3.

Ao final dos anos de 1940, pode-se dizer que a Nutrição estava institucionalizada como campo de saber. Seu esforço foi, principalmente, o de captar a especificidade do debate das ações e políticas públicas em torno de um projeto de segurança alimentar e por este meio projetar um projeto de desenvolvimento singular brasileiro para conduzir o país sem fome.

\section{Geografia da fome: fome, saúde e sociedade}

O resultado de suas reflexões e das pesquisas de campo na direção de políticas sociais de alimentação culminaram na elaboração do seu manifesto político-científico, Geografia da fome (1946), em que denuncia a fome como fenômeno político social. A nosso ver, essa obra é a síntese de seus estudos anteriores e é a base metodológica de seus escritos subsequentes. Além disso é fruto da colaboração do grupo de estudiosos de todo o Brasil, sobre a situação da fome, que elaborou um verdadeiro mapeamento da fome brasileira nos quatro cantos do país, subsidiado e patrocinado pelo SAPS.

Com suas várias edições, que foram realizadas nos anos de 1950 e 1960, Geografia da Fome apresentou-se como a tela sobre Brasil, pintada por Castro, que vai ganhando cores, matizes e contrastes na busca de construir uma sociedade democrática e moderna, fugindo das análises essencialistas e naturalizadora das desigualdades sociais e de interpretações e ações importadas de fora para dentro.

Para Castro, a saída para formação de um projeto nacional seria colocar em pauta a elaboração de um projeto equitativo entre as regiões brasileiras, economicamente e socialmente desiguais, através de planejamento de políticas agrícolas econômicas de abastecimento de alimentos, capaz de atender a todos os brasileiros.
O investimento na agricultura viabilizaria melhores condições de vida e produziria saúde para população.

Nesta fase, nota-se a influência do discurso nacional-desenvolvimentista, que tanto influenciou o movimento sanitarista neste período (sanitarismo-desenvolvimentista), liderado por Mário Magalhães. O sanitarismo desenvolvimentista buscou associar os problemas de saúde com os determinantes sociais, apostando que com a melhoria dos determinantes sociais, a produção de saúde da população se elevaria, em contraposição à ideia de que era o investimento inicial no setor da saúde a chave para modernização, ignorando as questões socioeconômicas ${ }^{30}$.

Nesse sentido, "Geografia da Fome" apresentou-se como um estudo de maior organicidade do pensamento de Castro em relação à fase 19301940, em que a concepção de ciclo vicioso (doença-pobreza-doença) parecia ser central na sua perspectiva, embora não tenha abandonado totalmente tal perspectiva, mas a partir dessa obra ela não se apresentaria como matriz de operacionalização de um progresso social.

$\mathrm{Na}$ obra em tela, o conceito de fome apresenta-se mais lapidado, marcado por uma mudança em relação aos estudos anteriores, em que fome e subnutrição apareciam frequentemente como sinônimos, trazendo grande impacto nos estudos sobre a realidade brasileira ${ }^{13}$. Ao adotar a fome como temática central revelou sua compreensão acerca da importância da transdisciplinaridade na abordagem da problemática, correlacionando fome ao problema do subdesenvolvimento brasileiro, como bem sinaliza Taranto ${ }^{31}$.

Em síntese, Geografia da fome traz à tona algumas das interpretações mais relevantes sobre a situação alimentar brasileira, lançando o primeiro manifesto-científico-propositivo para construção de um Plano de Política Pública de Segurança Alimentar no Brasil. Subjazem a esta sua discussão os aspectos do processo de construção do Estado-nação, o desenvolvimentismo nacional e o papel dos intelectuais brasileiros. Tais questões somam-se à preocupação do autor com a formação de ações propositivas que levassem a mudanças sociais e redefinições das condições de exclusão social de parcela significativa da população brasileira ${ }^{1}$.

Com a publicação de Geografia da Fome, Castro foi bastante criticado por ufanistas que o acusavam de desvalorizar o Brasil no estrangeiro. Entretanto, seguindo o mesmo método aplicado a esta obra, Castro escreveu "Geopolítica da Fome” (1951) para comprovar que a fome não 
era um fenômeno exclusivo do Brasil, mas de todos os países do globo, mas a forma de buscar soluções para tal problemática é que seria peculiar de cada país e cada região. Neste livro, "Geopolítica da Fome", Castro ${ }^{32}$ apresentou uma ampla discussão sobre neomalthusianismo, subdesenvolvimento e neocolonialismo.

Para Castro $^{32}$, nas preocupações dos neomalthusianos não constavam qualquer perspectiva de alteração da realidade, isto é, de modificação das estruturas econômicas e sociais ou das relações entre países ricos e pobres. Pelo contrário, constituíam agravantes ao culpabilizar os países pobres e os pobres, de forma geral, pelos males sociais. Assim como não mencionava a quem beneficiaria a preservação de "importantes recursos naturais”, já que, notadamente, eram os países mais desenvolvidos os responsáveis pela degradação do meio ambiente. Dessa maneira, em sua análise, o problema residia, de fato, no insustentável padrão de consumo das sociedades desenvolvidas e na manutenção dos privilégios de classe. Sendo assim, dependendo do modo de distribuição da renda e da riqueza, poder-se-ia ter o aumento da fome mesmo sem haver explosão demográfica ${ }^{32}$.

$\mathrm{Na}$ compreensão de Castro $^{32}$, a industrialização, a urbanização e o desenvolvimento científico possibilitaram expandir a produtividade de alimentos, que subverteria as condições de miséria e pobreza, mas não a fizeram tendo em vista seu caráter exclusivamente de exploração de trabalho, visando o lucro. Era necessário desvendar os interesses econômicos neocoloniais orientados de uma prática que fez da produção, da distribuição e do consumo de alimento, elementos dirigidos no sentido de seus exclusivos interesses financeiros e não sociais. Nesse sentido, era necessário admitir que a evolução científica e o progresso industrial não eram para todos e também poderiam ser responsáveis pela manutenção do status quo ${ }^{33}$.

Tais reflexões fizeram Castro relativizar a perspectiva progressista linear, a partir do diálogo com Sorokin (1889-1968), que não acreditava na perspectiva linear sobre os processos sócio -históricos. Assim, Castro partia do entendimento de que os processos socioculturais se revelavam multiformes e multidirecionais, sendo em algumas conexões lineares e em outras cíclicas. Além disso, com o processo de industrialização e exploração social no Ocidente, houve uma transformação integral de um mundo para o outro, onde as convicções sociais e os valores ganharam outro significado nos países colonizados ${ }^{32,34}$.
Para Castro, o problema da fome era de ordem socialmente construída pelo movimento neocolonianismo, o qual foi preponderante para a reprodução e a produção desse fenômeno social e para o qual a solução seria refundar nossas estruturas sociais, no caso brasileiro, a partir do investimento na agricultura, pautado por um Programa de Políticas Públicas de Segurança Alimentar. Com isso, Castro chama a atenção para a necessidade de o Brasil investir na elaboração e no planejamento de políticas agrícolas a partir de reformas sociais, como a reforma agrária.

Entretanto, Castro pontuava que sozinhos os países subdesenvolvidos não conseguiriam sair da calamidade social em que se encontravam, era necessário, para além de construir projetos políticos próprios, pensar o desenvolvimento a partir de uma economia social de cooperação internacional. Ao presidir a FAO (Food and Agriculture Organization of the United Nation) entre 19521956, concluiu que os países desenvolvidos, que estavam à frente da FAO, não tratavam com devida atenção os problemas de segurança alimentar dos países subdesenvolvidos. Assim, deixou o cargo sem tentar a reeleição ${ }^{9}$.

Logo após deixar a presidência da FAO, Castro fundou, junto com Abbé Pierre, na cidade de Paris, a Associação Mundial de Combate à Fome (ASCOFAM), tornando-se presidente da associação, que contava também com apoio de Louis Joseph Lebret, Lord Boyd Orr e René Dumont. A ASCOFAM surgiu como um manifesto inicialmente publicado em 30 páginas e, posteriormente, ampliado para 110 páginas que se tornou “ $\mathrm{O}$ Livro Negro da Fome” em 1960.

A escolha de escrever um livro-manifesto teve o objetivo de chamar a atenção para a necessidade de criação de um governo supranacional entre nações, povos e diferentes classes, voltado para a formulação de uma nova teoria do desenvolvimento econômico nos países subdesenvolvidos. Essa nova teoria deveria integrar os fatores humanos à Economia, de modo a fazer com que o desenvolvimento econômico fosse um meio de proporcionar dignidade a todos.

Esse manifesto foi publicado em vários idiomas e concentrou-se em quatro setores de atuação: 1) sensibilizar e despertar a consciência universal sobre o problema; 2) realizar pesquisa, investigações e inquéritos sobre a situação alimentar; 3) formar pessoal qualificado; 4) elaborar projetos específicos de âmbito nacional ou regional ${ }^{19}$.

Influenciado pela noção de "Desenvolvimento Harmonizado" de Lebret, Castro trabalhou 
para o reconhecimento do subdesenvolvimento através da fome e da exploração colonial, evidenciando a plataforma de reestruturação agrária como meio de empreender planos de desenvolvimento no campo rural e urbano do país a fim de construir uma sociedade sem fome ${ }^{35}$. O pressuposto era que o desenvolvimento econômico proposto não seria o caminho a ser trilhado para combater à fome. Fazia-se necessário pensar outro modelo de desenvolvimento, promovido por uma cooperação mundial com objetivo de criar fatores de proteção para os seres humanos, uma economia humanizada, voltada para o "desenvolvimento do homem pelo homem"19.

Cabe ressaltar que Castro ${ }^{19,20,32}$ deixa claro que era contra o capitalismo liberal, que operava a partir da livre iniciativa, geradora de caos ao conjunto da produção, distribuição e consumo de alimentos, mas também não se associava à planificação do socialismo, que considerava tecnocrática e ditatorial. Seu projeto de cooperação mundial vislumbrava uma terceira via com ativa participação das populações, das organizações civis e estatais, numa estrutura de poder descentralizado, mas com decisões coordenadas, visando o uso racional dos recursos naturais, sem descartar os avanços tecnológicos e industriais para atingir tais fins.

Ao negar a visão dualista de mundo (capitalismo x socialismo), Castro ${ }^{19}$ vislumbrava um sentimento de humanidade promovido por uma cooperação global suprapartidária, sem uma ideologia em si, mas com objetivo de pensar o mecanismo para uma economia humanizada, em que o papel participativo das populações seria ativo, haja vista que "os povos famintos passaram da resignação à revolta e, por isto, os povos da abundância terão que passar, sem perda de tempo, das explicações hipócritas à ação criadora" ou passaríamos a presenciar a degradação do mundo.

No debate atual, o paradigma do desenvolvimento foi substituído pelo da globalização e do papel do Estado frente à abertura dos mercados e ao aparecimento de numerosos atores multinacionais, que fizeram ainda mais com que a alimentação perdesse seu papel estratégico central na luta pelas desigualdades regionais e sociais, em consequência da sua visão neoliberal dominante, centralizada na especulação de mercado, que tenta a todo custo diminuir consideravelmente a importância das políticas públicas sociais e a cooperação internacional na solução do problema da segurança alimentar ${ }^{36}$.

Pela tese de Castro ${ }^{19,20,32}$, isso explicaria em parte o porquê da persistência da fome na contem- poraneidade, onde convivemos com abundância, com índices altíssimos de produção alimentar, e com condições de destruição humana por carência alimentar, negando as necessidades básicas de alguns seres humanos, para atender as exigências do capital em suas relações de produção ${ }^{37}$.

\section{Considerações finais}

Há várias revisitações sobre a trajetória e a obra de Josué de Castro, que se mantém em crescimento constante, com debates profícuos em torno do tema. Temática que se tornou símbolo das políticas sociais de muitos países da América Latina, sobretudo, no Brasil, nas primeiras décadas do milênio. Boa parte dos estudos são focalizados em sua obra magna "Geografia da Fome", que a nosso ver, poderá causar alguns equívocos de interpretação sobre ele, que se constituiu como um autor em processo de constante lapidação/atualização de seu pensamento, sem com isso perder a principal marca de seu pensamento, o ecletismo intelectual, o humanismo social e a luta contra a fome.

$\mathrm{Na}$ atualidade, a fome ainda é uma preocupação, sendo uma das pautas da agenda do milênio. Entretanto, é preciso não esquecer da premissa de que a fome é uma manifestação biológica de um problema social, portanto, produzido pelo próprio homem ${ }^{20}$. No caso específico do nosso modo de produção capitalista, que promove a desigual distribuição, colabora para desprover a massa populacional do acesso aos meios produtivos, fazendo com que os indivíduos tenham o acesso à alimentação condicionado pela renda. Desse modo, o direito básico da existência humana, tornou-se mercadoria. Uma mercadoria abundante, mas com acesso limitado. Quem delimita este acesso? O modo de produção escolhido pelas ações humanas. Assim, são nossas ações que contribuem para a reprodução diária, intencional e contínua da fome. Os dados dessa reprodução, ainda, são alarmantes. De acordo com o relatório da ONU (2014), há mais de 800 milhões de pessoas no mundo que ainda sofrem de fome crônica.

Como nos revela Ziegler" ${ }^{37}$, no seu livro "Destruição em Massa - Geopolítica da fome”, a fome ainda se constitui um grande problema mundial e vem aumentando na maioria dos países, com exceção do Brasil e da China, que contam com programas sociais, no caso brasileiro, e a reforma agrária no país asiático. Entretanto, no mundo inteiro há muito o que se fazer para evitar a destrui- 
ção em massa (a morte por causa da fome), que mata $1 \%$ da população a cada ano decorrente de fome quantitativa (fome epidêmica, como conceituada por Castro) e suas consequências mais diretas ou por causa da fome indireta; e (fome endêmica ou crônica, também analisada por Castro) que causa enfermidades devido à baixa imunidade, causada pela falta de alguns nutrientes. Ambas as manifestações da fome, atingem, atualmente, 18,2 milhões de pessoas por ano.

Ziegler $^{37}$ argumenta ainda que as grandes empresas de alimentos, que dominam a formação de mercado, são quem decide quem morrerá de fome. Isto porque a população pobre e extre- mamente pobre, que vive nas favelas, não produz e precisa comprar sua alimentação diária, e quando por causa das especulações os alimentos como milho, trigo, arroz sobe os preços dos demais alimentos sobem e a população pobre não tem renda para comprar. Devido a isso que mesmo Brasil e China, que apresentam melhoria da situação de fome, não estariam completamente seguros de novas crises ${ }^{37}$. Em Castro, observamos que a saída para tal problemática é a refundação da estrutura socioeconômica, visando uma economia humanizada, a partir de uma política econômica de cooperação, caso contrário nos autodestruiremos.

\section{Colaboradores}

MFS Silva e ED Nunes participaram igualmente de todas as etapas de elaboração do artigo. 


\section{Referências}

1. Silva MFS. Josué de Castro: um autor do legado esquecido? [tese]. Campinas: Universidade Estadual de Campinas; 2016.

2. Castro AM. Nutrição e desenvolvimento: análise de uma política [tese]. Rio de Janeiro: Instituto de Nutrição da UFRJ; 1977.

3. L'abbate S. Fome e Desnutrição: os descaminhos da política social [dissertação]. São Paulo: Universidade Estadual de São Paulo; 1982.

4. Magalhães R. Fome: uma(re)leitura de Josué de Castro. Rio de Janeiro: Fiocruz; 1997.

5. Vasconcelos FAG. Os Arquivos Brasileiros de Nutrição: uma revisão sobre produção científica em nutrição no Brasil (1944 a 1968). Cad Saude Publica 1999; 15(2):303-316.

6. Bizzo MLG. Agências Internacionais e agenda local: atores e ideias a interlocução entre nutrição e país (19321964) [tese]. Rio de Janeiro: Fundação Osvaldo Cruz; 2012.

7. Arruda BKG. Geografia da Fome: da lógica regional à universalidade. Rio de Janeiro: Cad Saude Publica 1997; 3(13):545-549.

8. Aguiar RC. O Rebelde Esquecido; Tempo, vida e obra de Manoel Bonfim. Rio de Janeiro: Topbooks; 2000.

9. Silva TEM. Josué de Castro: para uma poética da fome [tese]. São Paulo: Pontifícia Universidade Católica de São Paulo; 1998.

10. Tendler S. Josué de Castro, cidadão do mundo. [documentário]. Rio de Janeiro: Bárbara Produções; 1994.

11. Ribeiro D. Depoimento. In: Tendler S. Josué de Castro, cidadão do mundo. [documentário]. Rio de Janeiro: Bárbara Produções; 1994.

12. Candido A. Para pensar o problema da fome. Folha de São Paulo, 1999 Nov 29; Caderno C.

13. Souza J. A invisibilidade da desigualdade brasileira. Belo Horizonte: Editora UFMG; 2006.

14. Souza J. A modernidade seletiva: uma reinterpretação do dilema brasileiro. Brasília: Ed. UnB; 2000.

15. Bastos ER. Atualidade do pensamento social brasileiro. Soc. estado 2011;26(2):51-70.

16. Maia JME. Ao Sul da Teoria: A atualidade teórica do pensamento social brasileiro. Soc. estado 2011; 26(2):71-94

17. Souza J. A Ralé b: quem é e como vive. Belo Horizonte: UFMG; 2009.

18. Castro J. Ensaios de Biologia Social. São Paulo: Brasiliense; 1968

19. Castro J. O Livro Negro da Fome. São Paulo: Brasiliense; 1960.

20. Castro J. Geografia da Fome. O dilema brasileiro: pão ou aço. Rio de Janeiro: O Cruzeiro; 2005.

21. Freyre G. Casa-grande \& Senzala. 34a ed. Rio de Janeiro: Record; 1998

22. Rezende MJ. Celso Furtado e Karl Mannheim: uma discussão acerca do papel dos intelectuais nos processos mudança social. Revista Acta Scientiarum Human and Social Sciences 2004; 26(2):239-250.

23. Schappo S. Josué de Castro por uma agricultura de sustentação [tese]. Campinas: Universidade Estadual de Campinas; 2008.
24. Freyre G. Sobrados e Mocambos. São Paulo: Nacional; 1936.

25. Castro A. Fome, um tema proibido: últimos escritos de Josué de Castro. $3^{\text {a }}$ ed. Recife: Instituto de Planejamento de Pernambuco: Companhia Editora de Pernambuco; 1996.

26. Lima ES. Gênese e Constituição da Educação Alimentar: uma síntese. Physis 1997; 7(2):9-29.

27. Lima ES. Gênese e Constituição da Educação Alimentar: a instauração da norma. Hist. cienc. saude-Manguinhos 1998; 5(1):57-83.

28. Lima ES. Quantidade, qualidade, harmonia e adequação: princípios guia da sociedade sem fome em Josué de Castro. Hist. cienc. saude-Manguinhos 2009; 16(1):171-194

29. Lima NT, Hochman G. Condenado pela, absolvido pela medicina: o Brasil descoberto pelo movimento sanitarista da Primeira República. In: Maio MC, Santos R V organizadores. Raça, ciência e sociedade. Rio de Janeiro: Fiocruz, Centro Cultural Banco do Brasil; 1996. p. 2340

30. Araújo IMM. Saúde e Desenvolvimento no Brasil: o pensamento de Mário Magalhães da Silveira e de Josué de Castro [dissertação]. Recife: Universidade Federal de Pernambuco; 2014.

31. Taranto GD. Sociedade e subdesenvolvimento na obra de Josué de Castro. Belém: CEJUP; 1993.

32. Castro J. Geopolítica da fome: ensaio sobre os problemas de alimentação e de população. São Paulo: Brasiliense; 1968.

33. Rezende MJ. Colonialismo, subdesenvolvimento fome em Josué de Castro. Cadernos de Estudos Sociais 2003;19(2).

34. Rezende MJ. Josué de Castro e as combinações de perspectivas multidirecionais e cíclicas de mudanças sociais. Revista Ciências Humanas 2003; 33:117-145.

35. Rodan DD. Territórios do Desenvolvimento nos diálogos entre Josué de Castro e Louis-Joseph Lebret. [acessado 2017 Ago 09].2013 Disponível em: http://unuhospedagem.com.br/revista/rbeur/index.php/anais/article/ viewFile/4622/4491

36. Chonchol J. A soberania alimentar. In. Dossiê da América Latina. Revista Estudos Avançados 2005; 19(55):

37. Ziegler J. Destruição em massa geopolítica da fome. São Paulo: Cortez; 2013.

Artigo apresentado em 21/12/2016

Aprovado em 05/04/2017

Versão final apresentada em 07/04/2017 
